\title{
Hyperketonemia during lipopolysaccharide-induced mastitis affects systemic and local intramammary metabolism in dairy cows
}

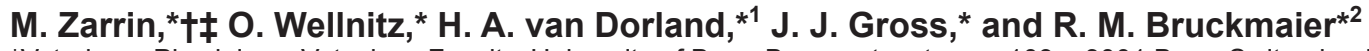 \\ *Veterinary Physiology, Vetsuisse Faculty, University of Bern, Bremgartenstrasse 109a, 3001 Bern, Switzerland \\ †Department of Animal Science, Agriculture Faculty, Yasouj University, Student Street, 75918-74831, Yasouj, I. R. Iran \\ †Graduate School for Cellular and Biomedical Sciences, University of Bern, Freiestrasse 1, 3012 Bern, Switzerland
}

\begin{abstract}
Hyperketonemia interferes with the metabolic regulation in dairy cows. It is assumed that metabolic and endocrine changes during hyperketonemia also affect metabolic adaptations during inflammatory processes. We therefore studied systemic and local intramammary effects of elevated plasma $\beta$-hydroxybutyrate (BHBA) before and during the response to an intramammary lipopolysaccharide (LPS) challenge. Thirteen dairy cows received intravenously either a Na-DL- $\beta$-OH-butyrate infusion $(\mathrm{n}=5)$ to achieve a constant plasma BHBA concentration $(1.7 \pm 0.1 \mathrm{mmol} / \mathrm{L})$, with adjustments of the infusion rates made based on immediate measurements of plasma BHBA every 15 min, or an infusion with a $0.9 \% \mathrm{NaCl}$ solution (control; $\mathrm{n}=8$ ) for $56 \mathrm{~h}$. Infusions started at $0900 \mathrm{~h}$ on $\mathrm{d} 1$ and continued until $1700 \mathrm{~h} 2$ d later. Two udder quarters were challenged with $200 \mu \mathrm{g}$ of Escherichia coli LPS and 2 udder quarters were treated with $0.9 \%$ saline solution as control quarters at $48 \mathrm{~h}$ after the start of infusion. Blood samples were taken at $1 \mathrm{wk}$ and $2 \mathrm{~h}$ before the start of infusions as reference samples and hourly during the infusion. Mammary gland biopsies were taken $1 \mathrm{wk}$

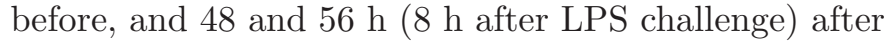
the start of infusions. The mRNA abundance of key factors related to BHBA and fatty acid metabolism, and glucose transporters was determined in mammary tissue biopsies. Blood samples were analyzed for plasma glucose, BHBA, nonesterified fatty acid, urea, insulin, glucagon, and cortisol concentrations. Differences were not different for effects of BHBA infusion on the mRNA abundance of any of the measured target genes in the mammary gland before LPS challenge. Intramammary LPS challenge increased plasma glucose, cortisol, glucagon, and insulin concentrations in both groups but
\end{abstract}

Received September 12, 2013.

Accepted February 10, 2014.

${ }^{1}$ Present address: School of Agricultural, Forest and Food Sciences, Bern University of Applied Sciences, Laenggasse 85, 3052 Zollikofen, Switzerland.

${ }^{2}$ Corresponding author: rupert.bruckmaier@vetsuisse.unibe.ch increases in plasma glucose and glucagon concentration were less pronounced in the Na-DL- $\beta$-OH-butyrate infusion group than in controls. In response to LPS challenge, plasma BHBA concentration decreased in controls and decreased also slightly in the BHBA-infused animals because the BHBA concentration could not be fully maintained despite a rapid increase in BHBA infusion rate. The change in mRNA abundance of citrate synthase in LPS quarters was significant between the 2 treatment groups. The results indicate that elevated circulating BHBA concentration inhibits gluconeogenesis before and during immune response to LPS challenge, likely because BHBA can replace glucose as an energy source.

Key words: metabolism, $\beta$-hydroxybutyrate, lipopolysaccharide challenge, mRNA abundance

\section{INTRODUCTION}

The markedly increased energy and nutrient requirements at simultaneously inadequate feed intake result in a negative energy balance (NEB) at the onset of lactation in dairy cows (van Dorland et al., 2009; Gross et al., 2011). A severe NEB leads to an increased mobilization of fat stores, an elevated uptake of NEFA by the liver, and an increase in plasma ketone body concentration (Bobe et al., 2004; Gross et al., 2011). The concentration of plasma BHBA, which is the major circulating ketone body in ruminants, is increased as a compensatory response to handle the excessive NEFA release during the NEB. $\beta$-Hydroxybutyrate functions as an energy source in many tissues, especially during NEB, and it seems also to be used for citrate synthesis in the mammary gland (Bionaz and Loor, 2008). An increase in plasma BHBA concentration beyond the threshold of 1,200 $\mu \mathrm{mol} / \mathrm{L}$ (Ospina et al., 2010) is generally accepted to represent the diagnosis of subclinical ketosis (Duffield et al., 2009). The increase in plasma ketone body concentration increases the risk of clinical ketosis, displaced abomasum, metritis, and subsequent decrease of milk production (Duffield et al., 2009). Elevated plasma BHBA concentration had a positive correlation with the severity of Escherichia coli masti- 
tis in an in vitro study (Kremer et al., 1993), and the risk of mastitis was much higher in subclinically ketotic dairy cows (Oltenacu and Ekesbo, 1994). An increase in plasma BHBA concentration to more than physiological range impairs metabolism in animals (Müller et al., 1984; Schlumbohm and Harmeyer, 2004; Zarrin et al., 2013). From the present study, 2 papers have been already published. Induced hyperketonemia was shown decrease 2 plasma glucose and glucagon concentrations, whereas it did not affect milk yield, feed intake, insulin, NEFA, urea, cortisol, and enzymes involved in gluconeogenesis (Zarrin et al., 2013). In addition, BHBA infusion caused increased acute-phase protein mRNA abundance in the mammary gland but not in the liver. The LPSrelated increase in SCC was less pronounced, whereas mRNA abundance of IL-8 and IL-10 increased more in the response to LPS in the group receiving BHBA infusion than in the control animals (Zarrin et al., 2014).

The use of intramammary LPS challenge to simulate IMI and to induce mastitis in dairy cows was established previously (Bruckmaier et al., 1993) to investigate the effect of mastitis on metabolism, immune responses, and performance in dairy cows. Evidence exists that LPS challenge affects metabolism and mRNA abundance of inflammatory and other factors (Bruckmaier et al., 1993; Waldron et al., 2006; Vernay et al., 2012). In addition, it causes a decline of milk production (Bannerman et al., 2003). However, no information exists about the effects of induced hyperketonemia at simultaneously even or positive energy balance on metabolic changes during mastitis.

The objective of this study was to induce long-term hyperketonemia beyond the threshold $(1.2 \mathrm{mmol} / \mathrm{L})$ through BHBA infusion for $56 \mathrm{~h}$, and additionally stimulate the immune system by intramammary LPS challenge to investigate systemic metabolic effects and changes of the mRNA abundance of genes related to metabolism in mammary tissue before and during the LPS challenge in mid-lactation dairy cows. Genes involved in FA synthesis [FA synthase $(\boldsymbol{F A} \boldsymbol{S} \boldsymbol{N})$ and acetyl-CoA carboxylase], tricarboxylic acid cycle [citrate synthase $(\boldsymbol{C S})]$, mammary BHBA metabolism [BHBA dehydrogenase $(\boldsymbol{B D H})$ 1, BDH2, succinylCoA:3-ketoacid-coenzyme A transferase 1 ( OXCT1)], and glucose transporters [glucose transporter $(\boldsymbol{G L} \boldsymbol{U} \boldsymbol{T})$ 1 and GLUT4] were selected to investigate the effects of elevated BHBA at simultaneously reduced glucose concentration on the mammary metabolism.

\section{MATERIALS AND METHODS}

\section{Animals and Management}

The animal trials followed the Swiss Law on Animal Protection and were permitted by the Committee of
Animal Experiments of the Canton Fribourg, Switzerland. To study the specific effect of BHBA infusion without the usual endocrine and metabolic changes during the transition period, 13 multiparous Holstein dairy cows (parity $3.5 \pm 0.1$; mean \pm SEM) in a later lactational stage $[28.0 \pm 0.3$ (mean \pm SEM) wk of lactation] were selected. Before the start of experiments, the health status of cows was checked by a routine blood glutaraldehyde coagulation test (Sandholm, 1976) and by measuring milk SCC (DeLaval cell counter DCC; Delaval International AB, Tumba, Sweden), which had to be less than $150 \times 10^{3}$ cells $/ \mathrm{mL}$ in all 4 quarters. Milking was performed twice daily at 0530 and $1600 \mathrm{~h}$.

Two weeks before the start of the experiment, animals were kept in a tie-stall barn for adaptation to the environment and feeding situations. All animals were fed ad libitum with hay (DM content $=890 \mathrm{~g} / \mathrm{kg}$ of fresh matter on a DM basis, consisting of $153 \mathrm{~g}$ of CP/ $\mathrm{kg}, 235 \mathrm{~g}$ of crude fiber $/ \mathrm{kg}$, and $5.7 \mathrm{MJ}$ of $\mathrm{NE}_{\mathrm{L}} / \mathrm{kg}$ ). In addition, they received a protein- and energy-rich concentrate $[23.5 \%$ barley, $14.0 \%$ oats, $20.0 \%$ wheat bran, $17.0 \%$ soybean expeller, $15.0 \%$ linseed meal, $0.6 \%$ salt, $2.2 \%$ carbonate of lime, $0.4 \%$ calf rearing feed premix, $4.0 \%$ molasses, and $3.0 \%$ bypass fat, on a DM basis (881 g/ kg of fresh matter), consisting of $217 \mathrm{~g}$ of $\mathrm{CP} /$ $\mathrm{kg}, 73.9 \mathrm{~g}$ of crude fiber $/ \mathrm{kg}$, and 7.6 $\mathrm{MJ}$ of $\mathrm{NE}_{\mathrm{L}} / \mathrm{kg}$, on a DM basis] twice daily according to individual milk production. Cows had free access to fresh water and minerals $(50 \mathrm{~g} / \mathrm{cow})$ were supplied daily.

\section{Experimental Design and Treatments}

Thirteen dairy cows were randomly assigned to 2 treatment groups. One group was intravenously infused with pyrogen-free and pH-balanced Na-DL- $\beta$ OH-butyrate (HyperB; $\mathrm{n}=5$ ) to achieve an elevated plasma BHBA concentration (1.5 to $2.0 \mathrm{mmol} / \mathrm{L})$, whereas the other group received a $0.9 \%$ saline solution (control; $\mathrm{n}=8$ ) for $56 \mathrm{~h}$. The infusions started at 0900 h on d 1 and continued until 1700 h 2 d later. Details on the preparation of solutions and infusion procedures are explained elsewhere (Zarrin et al., 2013).

At $48 \mathrm{~h}$ after infusion, 2 udder quarters were injected through the teat canal with $10 \mathrm{~mL}$ each of physiological $\mathrm{NaCl}$ (0.9\%), including $200 \mu \mathrm{g}$ of LPS E. coli serotype 026:B6 (no. L8274; Sigma-Aldrich, St. Louis, MO), and designated as LPS quarters, and $10 \mathrm{~mL}$ of $0.9 \% \mathrm{NaCl}$ was injected in 2 udder quarters as a control. Details are described elsewhere (Vernay et al., 2012).

\section{Data Collection and Sampling}

Blood Samples. Blood samples were taken 1 wk and $2 \mathrm{~h}$ before the start of infusions at $0730 \mathrm{~h}$, after milking, 
and before feeding, as reference samples and with sampling continuing hourly during the entire infusion period. On the day before the start of infusions, cows were fitted with indwelling intravenous catheters (Cavafix Certo Splittocan; B. Braun Melsungen AG, Melsungen, Germany) with a length of $32 \mathrm{~cm}$ and a diameter of 16 $\mathrm{G}$ in both jugular veins. Blood samples were collected into tubes, containing tripotassium EDTA, from the contralateral jugular catheter, which was not used for the infusion. Samples were immediately put on wet ice, centrifuged at $3,000 \times g$ for $20 \mathrm{~min}$ at $4^{\circ} \mathrm{C}$ and plasma was stored at $-20^{\circ} \mathrm{C}$ until analysis. During BHBA infusion, additional small blood samples $(1 \mathrm{~mL})$ were taken and analyzed immediately for adjustment of BHBA infusion rates every $5 \mathrm{~min}$ for the first $2 \mathrm{~h}$ and every 1 $\mathrm{h}$ thereafter.

Udder Biopsies. Details of the udder biopsy procedure were described by Vernay et al. (2012). In brief, $1 \mathrm{wk}$ before the start of infusions, before the LPS challenge ( $48 \mathrm{~h}$ after the start of infusions), and at the end of infusion ( $56 \mathrm{~h} ; 8 \mathrm{~h}$ after the LPS stimulation) udder tissue was taken from the 2 rear quarters (1 LPS and 1 control quarter). Before the biopsies, cows were sedated by an intravenous injection of $16 \mu \mathrm{g} / \mathrm{kg}$ of BW of xylazine (Xylazin Streuli ad us. vet.; G. Streuli \& Co. AG, Uznach, Switzerland). Udder tissue (30 to $60 \mathrm{mg}$ ) was obtained under local anesthesia with $10 \mathrm{~mL}$ of $2 \%$ lidocaine (Streuli Pharma AG, Uznach, Switzerland) using a biopsy needle $(12 \mathrm{G} \times 10 \mathrm{~cm}$; Bard Magnum Core Tissue Biopsy Needle; Bard GmbH, Türkenfeld, Germany). The samples were placed immediately into an RNA stabilization reagent (RNAlater, Ambion; Applied Biosystems Inc., Austin, TX), kept at $4^{\circ} \mathrm{C}$ for 24 $\mathrm{h}$, and stored thereafter at $-80^{\circ} \mathrm{C}$ until RNA extraction.

\section{Laboratory Procedures}

Blood Variables. Plasma glucose, BHBA, NEFA, and urea concentrations were measured enzymatically with an automated analyzer (Cobas Mira 2; HoffmannLa Roche, Basel, Switzerland), using commercial kits as described by van Dorland et al. (2009) and Kreipe et al. (2011). Plasma insulin concentration was measured by RIA as described by Vicari et al. (2008), and total cortisol was measured by RIA as described by Blum et al. (1985). Plasma glucagon concentration was measured by using a commercial RIA kit (catalog no. GL-32K; Millipore AG, Zug, Switzerland). In addition, the molar ratio of insulin:glucagon was calculated according the formula suggested by Muller et al. (1971).

Udder Tissue. Total RNA was extracted from udder tissues with peqGOLD TriFast (PEQLAB Biotechnologie GmbH, Erlangen, Germany). The quantity and purity of RNA was measured using a NanoDrop
ND-2000 spectrophotometer (NanoDrop Technologies Inc., Wilmington, DE). Complementary DNA was synthesized by reverse transcription of $1 \mu \mathrm{g}$ of total mRNA with the RNA-dependent DNA polymerase Moloney Murine Leukemia Virus Reverse Transcriptase RNase H Minus, Point Mutant (MMLV-RT; Promega Corp., Madison, WI) and random hexamer primers (Invitrogen, Leek, the Netherlands). The mRNA abundances of housekeeping genes (GAPDH and ubiquitin) and target genes related to udder metabolism were measured by real-time quantitative PCR (qPCR) in a Rotor-Gene 6000 rotary analyzer (Corbett Research, Sydney, Australia) using the software version 1.7.75. The cycle threshold (CT) values obtained from candidate genes were adjusted according the mean of the housekeeping gene $\mathrm{CT}$ according to the following equation: $\Delta \mathrm{CT}$ $=\mathrm{CT}$ (arithmetic mean of housekeeping genes) $-\mathrm{CT}$ (target gene). Differences in mRNA abundance of candidate genes (based on CT values) before the start of infusions and $48 \mathrm{~h}$ after the start of infusions were calculated as follows: $\Delta \Delta \mathrm{CT}=\Delta \mathrm{CT}[\mathrm{d} 3(0 \mathrm{~h})]-\Delta \mathrm{CT}$ (d 0), and differences in mRNA abundance by LPS challenge were calculated for LPS and control quarters separately according to this equation: $\Delta \Delta \mathrm{CT}=\Delta \mathrm{CT}$ [d $3(8 \mathrm{~h})]-\Delta \mathrm{CT}[\mathrm{d} 3(0 \mathrm{~h})]$. The primer sequences for FASN, CS, acetyl-CoA carboxylase, BDH2, GLUT1, and GLUT4 were published elsewhere (Graber et al., 2010). Succinyl-CoA:3-ketoacid-coenzyme A transferase 1 and BDH1 primers were designed to amplify cDNA. Selected primer sequences of housekeeping and measured genes encoding for mammary gland metabolism are shown in Table 1. The means \pm standard error of the mean of mRNA levels of $G A P D H$ and ubiquitin were stable across time points (baseline, $48 \mathrm{~h}$ after infusions, and at the end of infusions) and treatments (HyperB and $\mathrm{NaCl}$ ) are shown in Table 2.

\section{Statistical Analysis}

Before the statistical evaluation, all data were tested for normality in SAS (Release 9.2; SAS Institute Inc., Cary, NC; PROC UNIVARIATE plot normal), and all parameters followed a normal distribution. The changes (differences between before and $48 \mathrm{~h}$ after the start of infusions, and before and after LPS administration) were calculated for mRNA abundance of target genes. The area under the curve (AUC) was calculated for blood variables during the LPS challenge $(8.5 \mathrm{~h})$ by the trapezoidal rule (combination of rectangular and triangular area compartments). The respective plasma concentration before the start of infusion was used as baseline value.

The changes in mRNA abundance of measured genes and the AUC of blood variables were analyzed 
Table 1. Polymerase chain reaction primer information (For $=$ forward; Rev $=$ reverse), annealing temperature, and the PCR product length

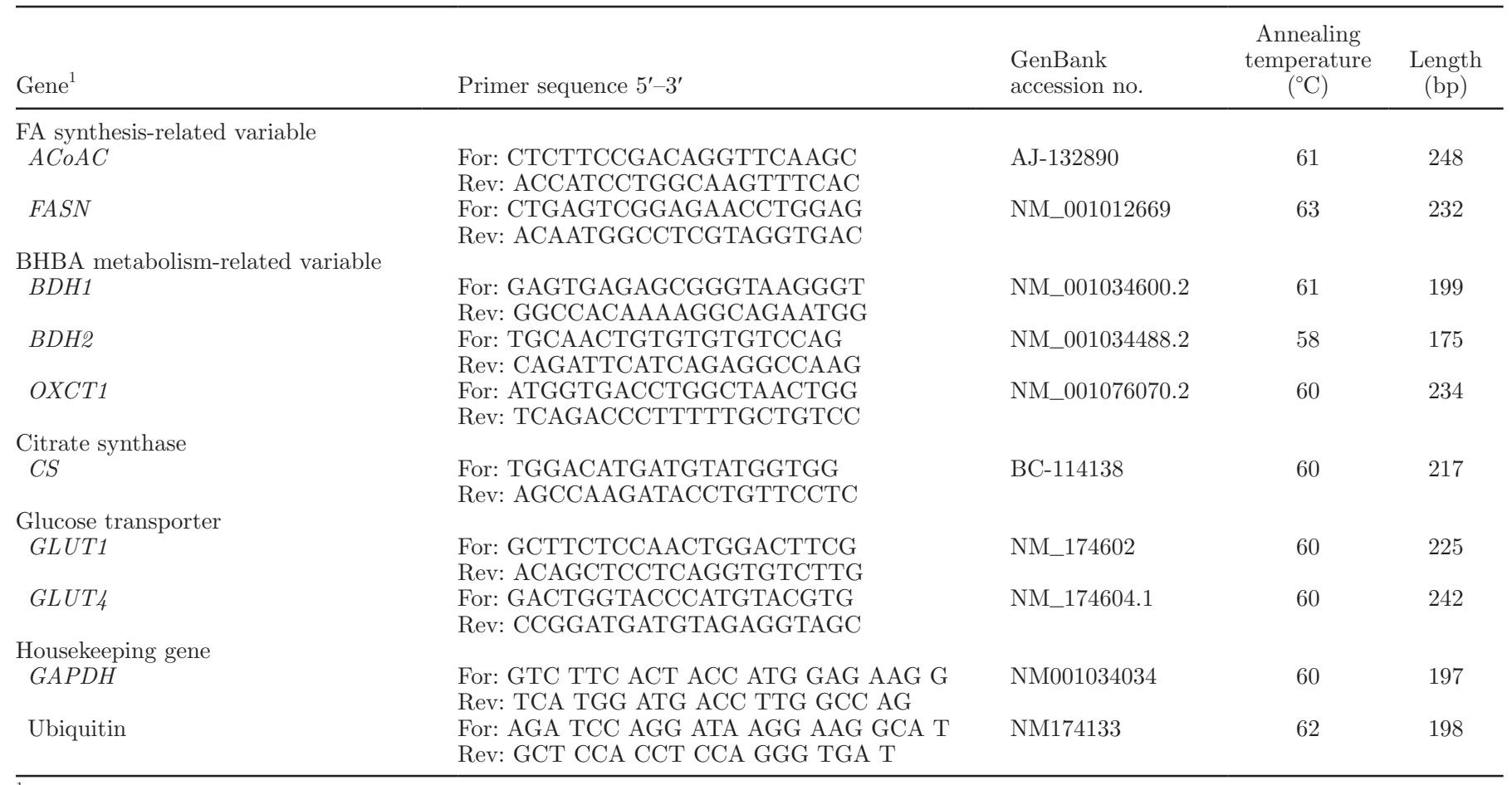

${ }^{1} A C o A C=$ acetyl-CoA carboxylase $F A S N=$ FA synthase $B D H 1=$ BHBA dehydrogenase $1 ; B D H 2=$ BHBA dehydrogenase $2 ; O X C T 1=$ succinyl-CoA:3-ketoacid-coenzyme A transferase 1; CS = citrate synthase; GLUT1 = glucose transporter $1 ; G L U T 4=$ glucose transporter 4.

by using the general linear models (GLM) procedure of SAS, including treatment (BHBA or $\mathrm{NaCl}$ ) as fixed effect. Differences between means were localized by the Tukey test. In addition, means of delta values obtained within each treatment were tested for their difference from 0. Differences in blood plasma variables between treatments within each time point and between time points within treatments were evaluated by using the PROC MIXED of SAS, including treatment (BHBA or $\mathrm{NaCl}$ ), time, and their interaction as fixed effects, and cows as repeated subject. The Tukey-Kramer test was used for adjustment of multiple comparisons. The compound symmetry structure was used for variance-covariance matrix for repeated measures within animals. Data are presented as means \pm standard error of the mean and differences were considered significant at $P<0.05$.

\section{RESULTS}

\section{Feed Intake, Milk Yield, and Infusion Rates and Concentrations of Plasma Variables}

As previously reported (Zarrin et al., 2013), DMI and milk yield were not affected by 48 -h BHBA infusion. Intramammary LPS challenge decreased DMI and milk yield in both treatment groups, whereas these variables were not affected by treatment (Table 3 ).

The AUC of plasma variable concentrations in the HyperB and control groups during the LPS challenge $(8.5 \mathrm{~h})$ is shown in Table 4. The mean BHBA infusion rate and plasma BHBA concentration in HyperB and control groups during -24 to $-48 \mathrm{~h}$ of infusion and hourly after LPS challenge are shown in Figure 1. The mean infusion rate of BHBA over $48 \mathrm{~h}$ was $8.1 \pm$

Table 2. Means \pm SEM of mRNA levels [cycle threshold (CT)] of housekeeping genes across time points and treatments

\begin{tabular}{|c|c|c|c|c|}
\hline Gene & Treatment $^{1}$ & Baseline & $\begin{array}{l}48 \mathrm{~h} \text { after } \\
\text { infusions }\end{array}$ & $\begin{array}{l}\text { End of } \\
\text { infusions }\end{array}$ \\
\hline \multirow[t]{2}{*}{$G A P D H$} & HyperB & $18.6 \pm 0.3$ & $17.9 \pm 0.2$ & $17.3 \pm 0.1$ \\
\hline & $\mathrm{NaCl}$ & $19.9 \pm 0.7$ & $19.3 \pm 0.7$ & $17.8 \pm 0.7$ \\
\hline \multirow[t]{2}{*}{ Ubiquitin } & HyperB & $16.8 \pm 0.4$ & $17.2 \pm 0.7$ & $16.6 \pm 0.2$ \\
\hline & $\mathrm{NaCl}$ & $19.1 \pm 0.4$ & $18.5 \pm 0.3$ & $18.1 \pm 0.5$ \\
\hline
\end{tabular}

${ }^{1}$ HyperB = infusion with BHBA $(\mathrm{n}=5) ; \mathrm{NaCl}=$ infusion with physiological saline solution $(\mathrm{n}=8)$. 
Table 3. Milk yield and DMI (mean \pm SEM) of dairy cows infused with BHBA (HyperB; $\mathrm{n}=5$ ) or saline $(\mathrm{NaCl} ; \mathrm{n}=8)$ before the start of the infusion (d 0), second day of infusion (d 2), and third day of infusion (day of LPS challenge)

\begin{tabular}{|c|c|c|c|c|c|c|c|}
\hline \multirow[b]{2}{*}{ Variable } & \multirow[b]{2}{*}{ Treatment } & \multicolumn{3}{|c|}{ Time relative to infusion } & \multicolumn{3}{|c|}{$P$-value } \\
\hline & & d 0 & d 2 & $\begin{array}{c}\text { d } 3 \\
\text { (LPS challenge) }\end{array}$ & Treatment & Time & $\begin{array}{l}\text { Treatment } \\
\times \text { time }\end{array}$ \\
\hline \multirow[t]{2}{*}{ Milk yield (kg/d) } & HyperB & $24.9 \pm 2.6$ & $22.0 \pm 2.6$ & $13.0 \pm 2.6$ & \multirow[t]{2}{*}{0.94} & \multirow[t]{2}{*}{$<0.01$} & \multirow[t]{2}{*}{0.43} \\
\hline & $\mathrm{NaCl}$ & $23.0 \pm 2.3$ & $20.6 \pm 2.0$ & $16.7 \pm 2.0$ & & & \\
\hline \multirow[t]{2}{*}{ DMI (kg/d) } & HyperB & $19.9 \pm 1.9$ & $19.0 \pm 1.9$ & $8.5 \pm 1.9$ & \multirow[t]{2}{*}{0.41} & \multirow[t]{2}{*}{$<0.001$} & \multirow[t]{2}{*}{0.17} \\
\hline & $\mathrm{NaCl}$ & $19.4 \pm 1.7$ & $18.1 \pm 1.5$ & $13.5 \pm 1.5$ & & & \\
\hline
\end{tabular}

$0.3 \mu \mathrm{mol} / \mathrm{kg}$ per minute. During 48-h BHBA infusion, the mean plasma BHBA concentration was maintained at $1.7 \pm 0.1 \mathrm{mmol} / \mathrm{L}$ in the HyperB group, and the plasma BHBA concentration in the control group was $0.6 \pm 0.1 \mathrm{mmol} / \mathrm{L}$. Intramammary LPS challenge decreased plasma BHBA concentration in the HyperB group from $1.7 \pm 0.1$ to $1.4 \pm 0.1 \mathrm{mmol} / \mathrm{L}(P<0.001)$ despite increased infusion rate. In the control group, plasma BHBA concentration decreased from $0.6 \pm 0.1$ to $0.4 \pm 0.1 \mathrm{mmol} / \mathrm{L}(P<0.01)$ compared with before LPS challenge. Because of the adjustment of the BHBA infusion rate to maintain hyperketonemia in the HyperB group, the mean BHBA infusion rate needed to be significantly increased $(P<0.001)$ to $11.1 \mu \mathrm{mol} /$ $\mathrm{kg}$ per minute after LPS administration. Despite the increased BHBA infusion rate in the HyperB group, the plasma BHBA concentration decreased in both groups $(P<0.05$; i.e., due to the fast change in BHBA plasma concentration, the maintenance of hyperketonemia in the HyperB group through increased infusion rate was not completely successful).

Plasma glucose, glucagon, insulin, NEFA, urea, and cortisol concentrations and the molar ratio of insulin:glucagon before the LPS challenge (average of 24-48 h of infusion), hourly after LPS stimulation $(8.5 \mathrm{~h})$, and their differences within treatments and between each time points are shown in Figures 2A, 2B, 2C, 3A, 3B, 3C, and 4. Compared with the plasma glucose concentration before the LPS challenge, intramammary LPS administration caused an increase in plasma glucose concentration in both infusion groups up to $90 \mathrm{~min}$. Plasma glucose concentration was decreased at $150 \mathrm{~min}$ after the LPS challenge, after that increased again at $210 \mathrm{~min}$, and finally decreased to the same concentration as before LPS administration. The increase in plasma glucose concentration after LPS administration was lower in HyperB than in the control $(P<0.05$; Figure 2A; Table 4$)$.

On the second day of hyperketonemia, treated cows had, on average, lower glucagon concentrations than control cows. Intramammary LPS treatment increased the glucagon concentration after $3.5 \mathrm{~h}$, which persisted for the remaining sampling period $(8.5 \mathrm{~h})$. During this time period, glucagon concentrations were lower in hyperketotic than control cows $(P<0.05$; Figure $2 \mathrm{~B})$, indicating that hyperketonemia attenuates the LPSinduced glucagon secretion $(P<0.05$; Table 4$)$.

In comparison with 48-h BHBA infusion, plasma insulin increased $(P<0.05$; Figure $2 \mathrm{C})$ in response to LPS challenge and reached a peak at $210 \mathrm{~min}$ in the HyperB group and at 270 min in the control group. Based on the AUC, plasma insulin concentration did not differ between the HyperB and control groups (Table 4). Plasma NEFA concentration was not affected by the LPS challenge and BHBA infusion (Figure 3A; Table 4).

Table 4. Plasma variable concentrations in dairy cows infused with BHBA (HyperB; $\mathrm{n}=5$ ) or saline $(\mathrm{NaCl} ; \mathrm{n}=8)$ during the LPS challenge ${ }^{1}$

\begin{tabular}{|c|c|c|c|c|c|}
\hline Variable & \multicolumn{2}{|c|}{ Treatment } & \multicolumn{3}{|c|}{$P$-value } \\
\hline BHBA (mmol/L·h) & $0.4 \pm 0.0$ & $1.4 \pm 0.1$ & 0.03 & $<0.001$ & $<0.001$ \\
\hline NEFA $(\mathrm{mmol} / \mathrm{L} \cdot \mathrm{h})$ & $0.1 \pm 0.0$ & $0.1 \pm 0.0$ & 0.81 & 0.20 & 0.76 \\
\hline Urea $(\mathrm{mmol} / \mathrm{L} \cdot \mathrm{h})$ & $4.0 \pm 0.3$ & $3.7 \pm 0.3$ & 0.02 & 0.07 & 0.44 \\
\hline Glucagon $(\mathrm{pg} / \mathrm{mL} \cdot \mathrm{h})$ & $221.7 \pm 15.3$ & $161.2 \pm 19.3$ & $<0.001$ & 0.08 & 0.03 \\
\hline Insulin:glucagon (molar ratio·h) & $3.7 \pm 0.7$ & $4.4 \pm 0.9$ & 0.03 & 0.02 & 0.52 \\
\hline
\end{tabular}

${ }^{1}$ Data are presented as LSM \pm SEM of area under the curve (AUC) during $8 \mathrm{~h}$. The AUC was calculated according to the trapezoidal rule. 


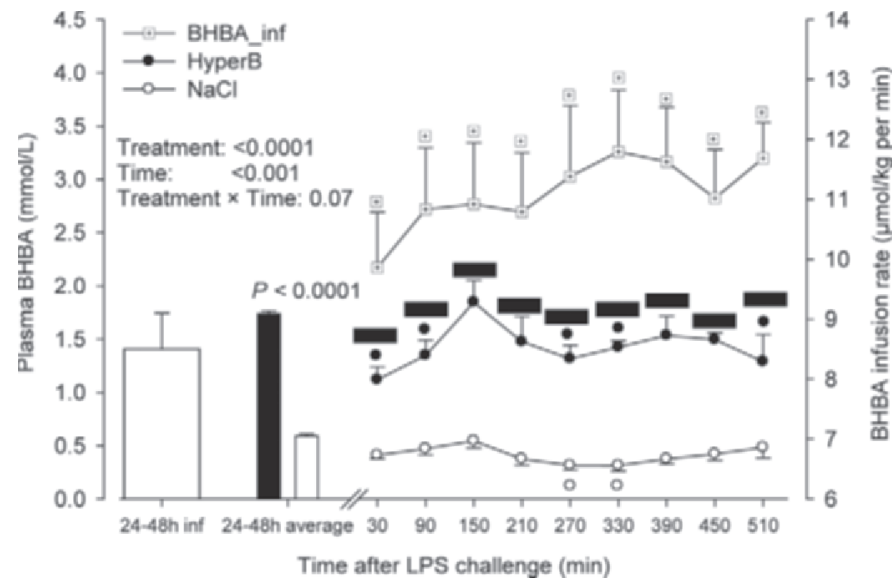

Figure 1. Mean BHBA infusion rate during -24 to $-48 \mathrm{~h}$ of infusion (24-48h inf) and hourly after LPS challenge (510 min) in BHBA cows (HyperB; $\mathrm{n}=5$ ). Mean plasma BHBA concentration in cows infused with BHBA (HyperB) and control cows $(\mathrm{NaCl} ; \mathrm{n}=8)$ during $48 \mathrm{~h}$ of infusion, -24 to $-48 \mathrm{~h}$ average and hourly after LPS challenge (510 min). Values represent mean \pm SEM. The open squares with plus signs show significant differences $(P<0.05)$ of BHBA infusion rate during the LPS challenge to mean infusion rates in -24 to -48 h. The closed circles and open circles show significant differences $(P$ $<0.05$ ) between -24 to $-48 \mathrm{~h}$ average and each time point during the LPS challenge for the HyperB and $\mathrm{NaCl}$ groups, respectively. The closed rectangles indicate significant differences between the 2 treatment groups during the LPS challenge $(P<0.05)$.

Intramammary LPS administration induced a decrease in plasma urea concentration only in the first 90 min after the LPS challenge in the HyperB group, whereas LPS challenge decreased the plasma urea concentration in the first $30 \mathrm{~min}$ in the control group $(P<$ 0.05; Figure 3B). Urea concentrations were not affected by infusion treatments (Table 4).

Plasma cortisol concentration was increased at 90 min after the intramammary LPS stimulation in both treatment groups $(P<0.05$; Figure $3 \mathrm{C})$, but based on the AUC, cortisol concentration did not differ between the HyperB and control groups (Table 4).

The insulin:glucagon molar ratio was not affected by the treatments at the second day of infusion and during the LPS challenge, whereas it was affected by intramammary LPS challenge at 3.5 and $4.5 \mathrm{~h}$ in the HyperB and control groups, respectively (Figure 4; Table 4).

\section{mRNA Abundance of Candidate Genes Related to Mammary Gland Metabolism}

mRNA Abundance Related to Mammary Metabolism During the $48 \mathrm{~h}$ of BHBA Infusion. The mRNA abundance of genes related to mammary gland metabolism before and $48 \mathrm{~h}$ after the start of infusions are shown in Table 5. Fatty acid synthase mRNA abundance decreased within the HyperB group during $48 \mathrm{~h}$ of BHBA infusion $(P<0.05$; Table 5$)$. The
mRNA abundances of the other candidate genes were not affected by 48-h BHBA infusion.

mRNA Abundance of Genes Related to Mammary Metabolism During the LPS Challenge. For both groups, differences between mRNA abundance of genes related to mammary gland metabolism before and after the LPS challenge in quarters stimulated with intramammary LPS and control quarters are shown in Table 6. Citrate synthase mRNA abundance in LPS quarters increased in the HyperB group and decreased in the control group after the LPS challenge $(P<0.05$; Table 6). Intramammary LPS challenge decreased mRNA abundance of BDH2, FASN, and OXCT1 in LPS quarters of both treatment groups, and decreased BDH1 and GLUT4 mRNA abundance in the control group $(P<0.05)$. Infusion of BHBA decreased BDH2 mRNA abundance in control quarters in the HyperB group $(P<0.05)$ after the LPS challenge. The mRNA abundance of other candidate genes in control quarters were not affected by LPS challenge and BHBA infusion in both treatment groups.

\section{DISCUSSION}

To our best knowledge, this experiment is the first study to investigate effects of an induced long-term (56 h) hyperketonemia, without other metabolic effects of NEB, on mammary gland metabolism and metabolic and endocrine parameters in combination with an activation of immune response by an intramammary LPS administration in mid-lactation dairy cows.

The effects of induced hyperketonemia for $48 \mathrm{~h}$ on blood metabolites, feed intake, mRNA abundance of candidate genes related to hepatic metabolism, and milk yield have been reported earlier (Zarrin et al., 2013). The moderate effects of BHBA infusion on mammary gland metabolism at the mRNA level confirmed that milk synthesis was not affected by intravenous BHBA infusion in mid-lactation dairy cows (Zarrin et al., 2013). The lacking effect on milk synthesis was likely due to the related low needs of glucose for mammary lactose synthesis and other metabolic processes at this lactational stage compared with early lactation. Thus, the reduced plasma glucose levels during BHBA infusion were likely not limiting for milk secretion.

Intramammary LPS challenge decreased plasma BHBA concentration in both treatment groups. The goal to maintain plasma BHBA at $1.7 \mathrm{mmol} / \mathrm{L}$ through an increased BHBA infusion rate could not be achieved because the decline in plasma BHBA concentration was faster than the possible adjustment of infusion rate. Waldron et al. (2003) suggested that the decline in plasma BHBA concentration was related to the suppression of ruminal epithelium ketogenesis capacity after LPS 
challenge. Because the decline in BHBA concentration after LPS administration was quite rapid and pronounced, a contribution of changed ruminal absorption may be excluded. Despite not doing a mammary LPS challenge, intramuscularly applied LPS in a different species decreased hepatic ketogenesis capacity (Memon et al., 1992), whereas LPS administration did not affect hepatic ketogenesis capacity in incubated liver slices of dairy cows (Waldron et al., 2003). Based on the fast and huge changes in plasma BHBA concentration in BHBA-infused animals in the present study, this effect seems very unlikely. Recent findings showed that LPS challenge increased milk BHBA concentration in LPS-treated quarters during an induced hyperketonemia (Lehmann et al., 2013). Thus, a certain quantity of BHBA is lost with the secreted milk in LPS-stimulated quarters. However, this portion does not seem to be quantitatively of great importance because milk secretion is reduced in the quarters treated with LPS.

A transient increase and a subsequent decrease in plasma glucose concentration after LPS challenge in both groups in this study was consistent with previous studies that illustrated transient hyperglycemia after E. coli endotoxin-induced mastitis (Bruckmaier et al., 1993), with increased and subsequent decreased plasma glucose concentration after LPS challenge (Werling et al., 1996). Hypoglycemia after the LPS challenge can also be attributed to increases in cytokines such as tumor necrosis factor $\alpha$ and IL-1 $\beta$ (Schmitz et al., 2004; Vernay et al., 2012; Zarrin et al., 2014), which increase glucose utilization during the LPS challenge (Stouthard et al., 1995). Regarding the increase in plasma glucose concentration after the LPS challenge, during a similar immune stimulation via LPS challenge previously, development of insulin resistance was reported and, in this case, the glucose infusion rate had to be reduced to avoid an increase in plasma glucose concentration; thus, additional glucose was available through either glycogenolysis or gluconeogenesis (Vernay et al., 2012). Based on present data it seems that the initial increase in plasma glucose concentration after LPS challenge is not related to glycogenolysis, because LPS challenge increased plasma glucagon concentration 150 min after LPS administration. The difference between plasma glucose concentrations in the 2 experimental groups after the LPS challenge was related to the BHBA infusion that decreased glucose production besides decreasing gluconeogenesis during LPS. The low plasma glucose concentration in the HyperB group rather than in the control group may be related to the reduced increase in plasma glucagon concentration in HyperB compared with the control group, which resulted in low glucose production from gluconeogenesis or glycogen storage (Zarrin et al., 2013).
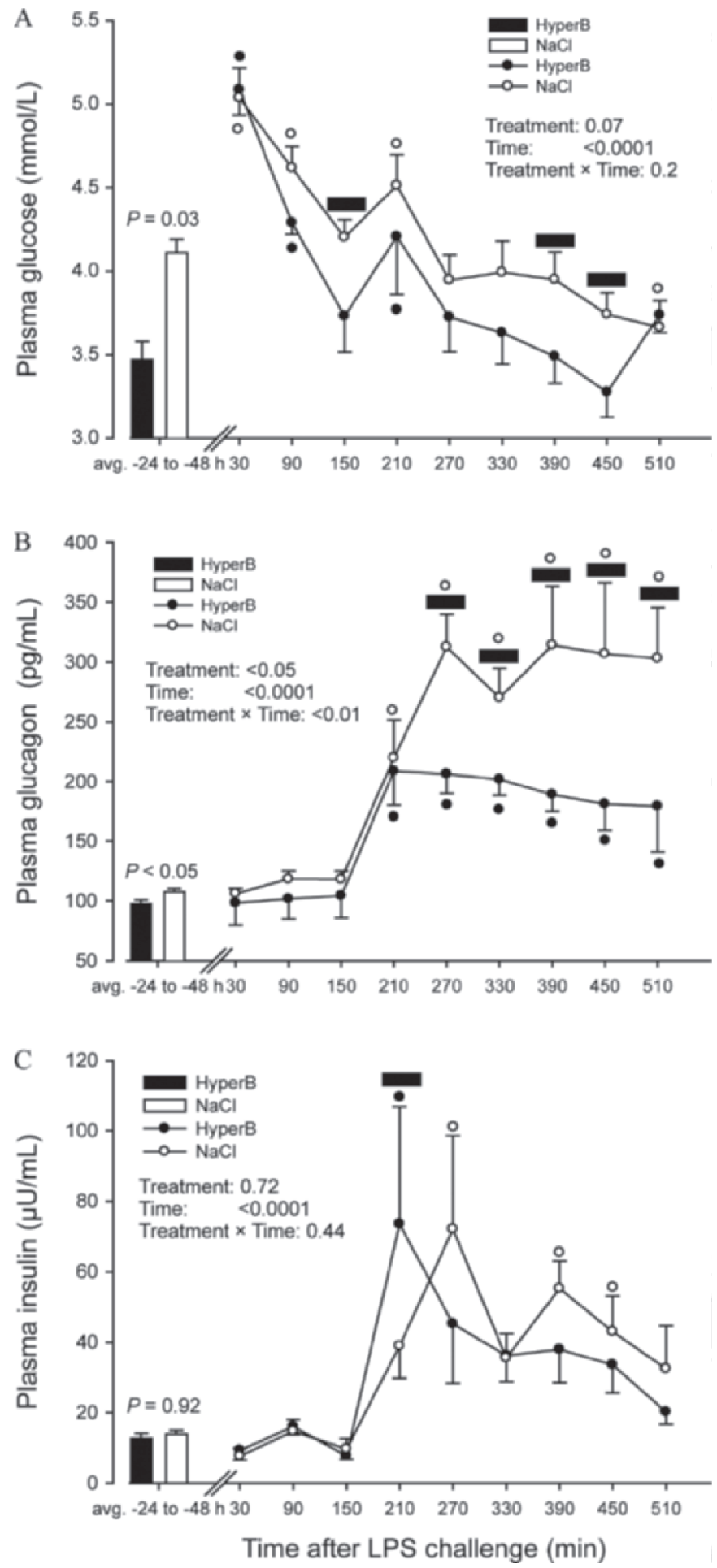

Figure 2. Mean plasma glucose (A), glucagon (B), and insulin (C) concentrations in cows infused with BHBA (HyperB; $\mathrm{n}=5)$ and control cows $(\mathrm{NaCl} ; \mathrm{n}=8)$ during $48 \mathrm{~h}$ of infusion $(-24$ to $-48 \mathrm{~h}$ average $)$ and hourly after LPS challenge (510 min). Values represent mean \pm SEM. The closed circles and open circles show significant differences $(P<0.05)$ between -24 to $-48 \mathrm{~h}$ average and each time point during the LPS challenge for the HyperB and $\mathrm{NaCl}$ groups, respectively. The closed rectangles indicate significant differences between the 2 treatment groups during the LPS challenge $(P<0.05)$. 

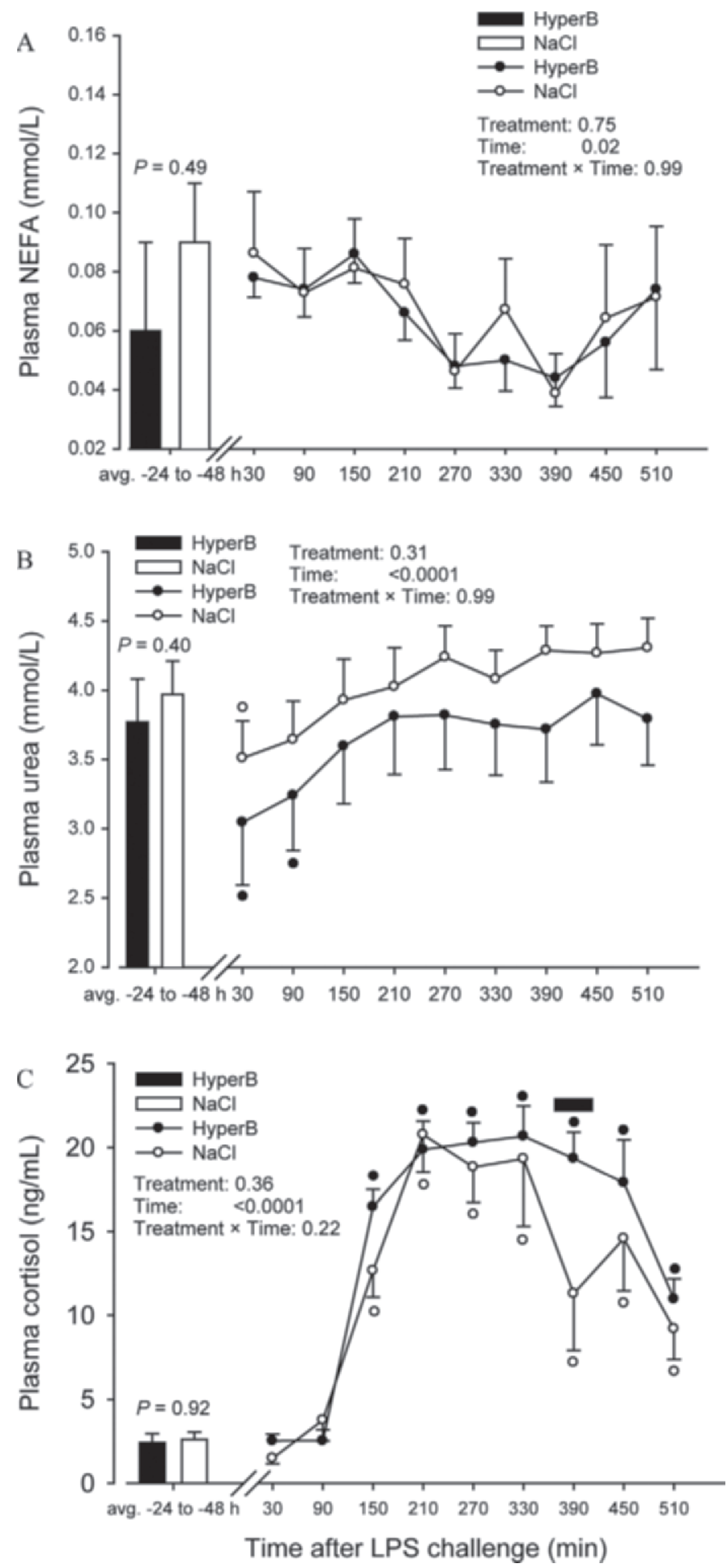

Figure 3. Mean plasma NEFA (A), urea (B), and cortisol (C) concentrations in cows infused with BHBA (HyperB; $\mathrm{n}=5$ ) and control cows ( $\mathrm{NaCl} ; \mathrm{n}=8)$ during $48 \mathrm{~h}$ of infusion $(-24$ to $-48 \mathrm{~h}$ average) and hourly after LPS challenge (510 min). Values represent mean \pm SEM. The closed circles and open circles show significant differences $(P<0.05)$ between -24 to $-48 \mathrm{~h}$ average and each time point during the LPS challenge for the HyperB and $\mathrm{NaCl}$ groups, respectively. The closed rectangle indicates significant difference between the 2 treatment groups during the LPS challenge $(P<0.05)$.

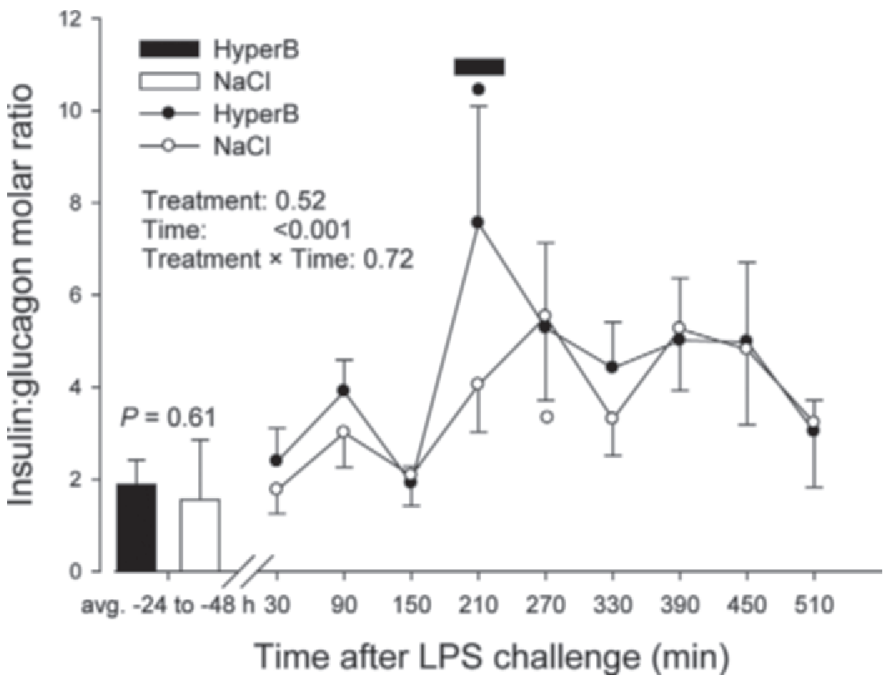

Figure 4. Insulin:glucagon molar ratio in cows infused with BHBA (HyperB; $\mathrm{n}=5$ ) and control cows $(\mathrm{NaCl} ; \mathrm{n}=8)$ during $48 \mathrm{~h}$ of infusion ( -24 to $-48 \mathrm{~h}$ average) and hourly after LPS challenge (510 min). Values represent mean \pm SEM. The closed circles and open circles show significant differences $(P<0.05)$ between -24 to -48 h average and each time point during the LPS challenge for the HyperB and $\mathrm{NaCl}$ groups, respectively. The closed rectangle indicates significant difference between the 2 treatment groups during the LPS challenge $(P<0.05)$.

Intramammary LPS challenge did not affect plasma NEFA concentration in the present study. This finding is in agreement with a previous study that showed that intramammary LPS challenge did not affect plasma NEFA concentration, whereas plasma NEFA concentration increased in control cows that received $\mathrm{NaCl}$ (Waldron et al., 2006). The results of the present study are in contrast with a previous study where different doses of LPS were administrated intravenously for $100 \mathrm{~min}$ in mid-lactation dairy cows and plasma NEFA tended to increase after LPS challenge (Waldron et al., 2003). In our previous study, intramammary LPS challenge caused a decrease in plasma NEFA concentration in mid-lactation dairy cows during hypoglycemic and euglycemic clamping, which manipulated plasma glucose concentration (Vernay et al., 2012). It can be assumed that in the present study, the unaffected plasma NEFA concentration following LPS challenge was related to the use of BHBA as an alternative energy source, which could diminish the mobilization of FA from fat stores in the HyperB group.

As previously observed in response to intramammary LPS administration (Lehtolainen et al., 2003; Waldron et al., 2006; Vernay et al., 2012), plasma cortisol concentration increased in both treatment groups. Proinflammatory cytokines and possibly also the handling of the animals during the experiments likely activated the hypothalamus-pituitary-gland axis and increased the synthesis of glucocorticoids (Beishuizen and Thijs, 
Table 5. Changes in mRNA abundance of genes related to mammary gland metabolism during $48 \mathrm{~h}$ of infusion with BHBA (HyperB; $\mathrm{n}=5)$ or saline $(\mathrm{NaCl} ; \mathrm{n}=8)$

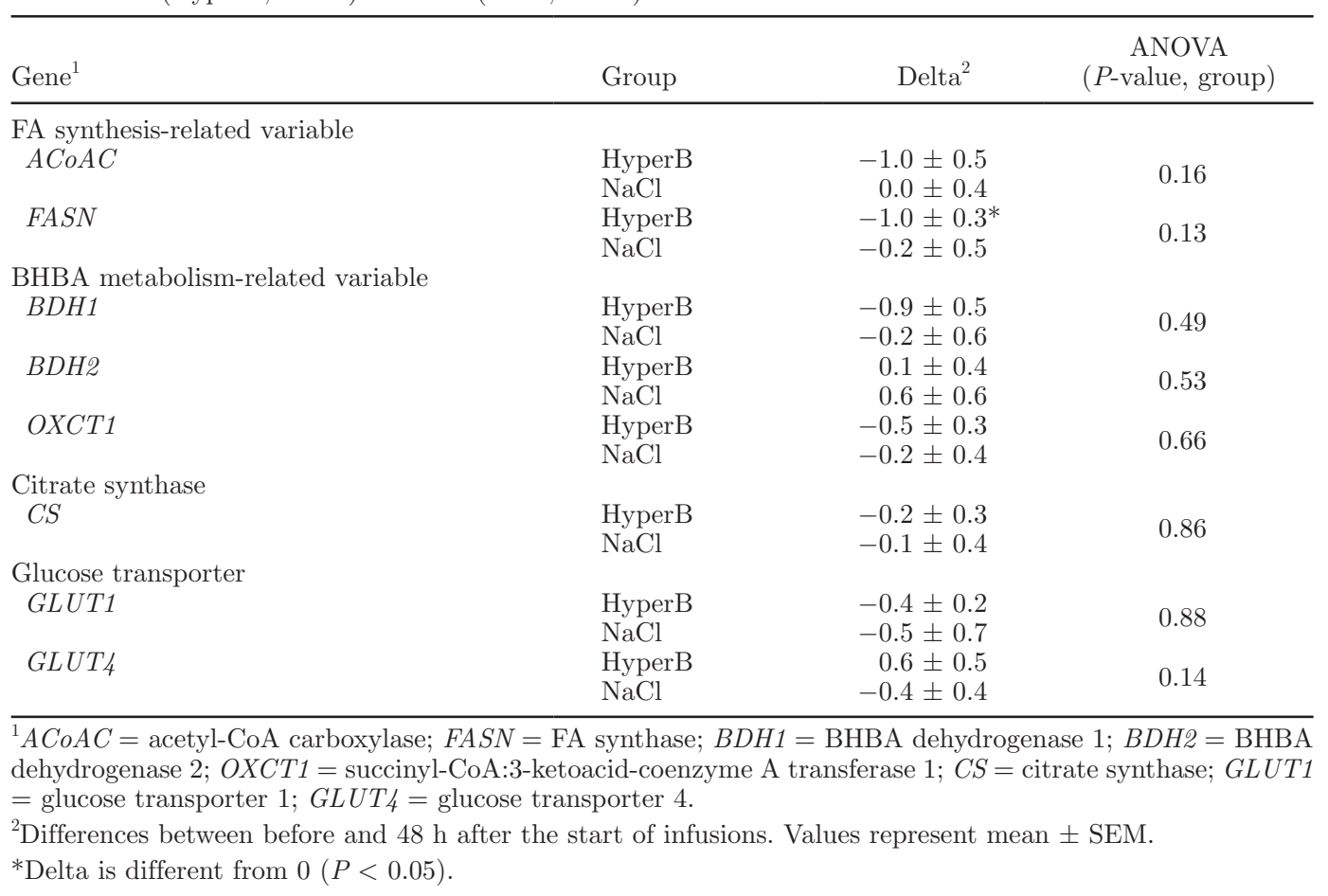

2003). Elevation of plasma cortisol concentration may be partially responsible for the observed induction of insulin resistance (Andrews and Walker, 1999) to provide more glucose for the immune reaction.
The increase in glucagon concentration after LPS administration is in agreement with Waldron et al. (2003), who reported plasma glucagon concentration being increased at $2 \mathrm{~h}$ after the LPS challenge and

Table 6. Differences in mRNA abundance related to metabolism in the mammary gland during the LPS challenge in LPS and control quarters in dairy cows infused with BHBA (HyperB; $\mathrm{n}=5)$ or saline $(\mathrm{NaCl} ; \mathrm{n}=8)$

\begin{tabular}{|c|c|c|c|c|c|}
\hline Gene $^{1}$ & Group & $\begin{array}{l}\text { LPS delta } \\
\text { (after LPS - }_{\text {before LPS) }}^{2}\end{array}$ & $\begin{array}{c}\text { ANOVA } \\
\text { (P-value, } \\
\text { group) }\end{array}$ & $\begin{array}{l}\text { Control delta } \\
\text { (after LPS - }^{2} \\
\text { before LPS) }\end{array}$ & $\begin{array}{c}\text { ANOVA } \\
\text { (P-value, } \\
\text { group) }\end{array}$ \\
\hline & $\mathrm{NaCl}$ & $-0.5 \pm 0.6$ & 0.66 & $-1.1 \pm 0.7$ & 0.58 \\
\hline$F A S N$ & HyperB & $-4.4 \pm 0.7^{*}$ & \multirow{2}{*}{0.60} & $-1.0 \pm 1.2$ & \multirow{2}{*}{0.47} \\
\hline & $\mathrm{NaCl}$ & $-3.8 \pm 0.8^{*}$ & & $-0.2 \pm 0.5$ & \\
\hline BDH2 & HyperB & $-2.6 \pm 0.4^{*}$ & \multirow[b]{2}{*}{0.87} & $-1.3 \pm 0.5^{*}$ & \multirow[b]{2}{*}{0.62} \\
\hline & $\mathrm{NaCl}$ & $-2.4 \pm 0.8^{*}$ & & $-1.0 \pm 0.5$ & \\
\hline$O X C T 1$ & HyperB & $-1.8 \pm 0.3^{*}$ & \multirow{2}{*}{0.25} & $0.3 \pm 0.7$ & \multirow{2}{*}{0.56} \\
\hline & $\mathrm{NaCl}$ & $-1.0 \pm 0.5^{*}$ & & $1.7 \pm 1.8$ & \\
\hline \multicolumn{6}{|c|}{ Citrate synthase } \\
\hline$C S$ & HyperB & $0.5 \pm 0.3$ & 0.05 & $-0.4 \pm 0.3$ & 0.35 \\
\hline GLUI4 & $\mathrm{NaCl}$ & $-2.0 \pm 0.5^{*}$ & 0.24 & $\begin{array}{l}0.8 \pm 0.8 \\
0.4 \pm 0.6\end{array}$ & 0.24 \\
\hline
\end{tabular}

${ }^{1} A C o A C=$ acetyl-CoA carboxylase $; F A S N=$ FA synthase; $B D H 1=$ BHBA dehydrogenase $1 ; B D H 2=$ BHBA dehydrogenase $2 ;$ OXCT1 $=$ succinyl-CoA:3-ketoacid-coenzyme A transferase 1; $C S=$ citrate synthase; GLUT1 = glucose transporter 1; GLUT4= glucose transporter 4 .

${ }^{2}$ Values are represented as mean \pm SEM.

*Delta is different from $0(P<0.05)$. 
staying at a high level up to $8 \mathrm{~h}$ after the start of LPS challenge. In the current study, increased plasma glucagon concentration in both groups was observed at 150 min after the intramammary LPS administration. However, the increase in plasma glucagon concentration during LPS challenge was much less in cows that received BHBA compared with controls. As reported previously, BHBA infusion decreased glucagon secretion (Zarrin et al., 2013), probably mediated by the inhibitory effect of gamma amino butyric acid (GABA) on glucagon secretion (Adeghate et al., 2000; Wendt et al., 2004), which increased in the epileptic brain in the presence of high plasma BHBA concentration (Suzuki et al., 2009). The less pronounced increase in glucagon concentration during LPS challenge in the HyperB group was likely related to a lower need for glucose for the immune response than in the control group and, thus, less activation of gluconeogenesis. This effect is another indicator for BHBA to be an alternative energy source.

An increased plasma insulin concentration in response to the LPS challenge in the present study is in agreement with previous studies (Waldron et al., 2003, 2006; Vernay et al., 2012). Despite the inhibitory effect of insulin on glucagon secretion (Weir et al., 1976), plasma glucagon concentration increased after LPS challenge. The effect of LPS challenge on glucoregulatory hormones is most likely related to effects of proinflammatory cytokines (Eizirik et al., 1995; Andersson et al., 2001), which stimulate the pancreatic production and release of these hormones.

The effect of the intramammary LPS challenge on FASN, OXCT1, and BDH2 mRNA abundance in quarters stimulated with LPS in both groups, and decrease in $C S$ mRNA abundance in the control group showed that LPS challenge negatively affects mammary gland metabolism and milk synthesis, which had been reported before (Waldron et al., 2003, 2006). The increase in $C S$ mRNA abundance in the HyperB group after LPS challenge is in agreement with Bionaz and Loor (2008), who suggested that the major product of BHBA metabolism in the bovine mammary gland is citrate, which is increased in milk. It can be assumed that the upregulation of mammary gland $C S$ mRNA abundance in the HyperB group confirmed that BHBA can be partly used to produce energy through the tricarboxylic acid cycle by mammary gland (Palmquist et al., 1969).

\section{CONCLUSIONS}

Results demonstrate that BHBA represents an alternative energy source for the mammary tissues and for the immune system. With respect to milk secretion and the related specific need of glucose, the BHBAinduced adaptions may cause an inadequate decline in plasma glucose concentration. It can be speculated that the resulting low plasma glucose concentration also negatively affects the immune response. The current results may reflect the negative effect of spontaneous hyperketonemia on hepatic gluconeogenesis by providing less glucose. Long-term reduced glucose availability caused by hyperketonemia might lower the productive performance of dairy cows.

\section{ACKNOWLEDGMENTS}

This study was supported by a grant of the Swiss National Foundation (Bern, Switzerland; grant no. 320030-120317). We thank Yolande Zbinden, Claudine Morel, and Chantal Philipona (Veterinary Physiology, Vetsuisse Faculty, University of Bern, Switzerland) for their support in the laboratory analyses. The authors also thank Martin Vernay and Luisa De Matteis (both from Veterinary Physiology, Vetsuisse Faculty, University of Bern, Berm, Switzerland) for their contributions to the animal experiments.

\section{REFERENCES}

Adeghate, E., A. S. Ponery, D. J. Pallot, and J. Singh. 2000. Distribution of neurotransmitters and their effects on glucagon secretion from the in vitro normal and diabetic pancreatic tissues. Tissue Cell 32:266-274.

Andersson, A. K., M. Flodström, and S. Sandler. 2001. Cytokine induced inhibition of insulin release from mouse pancreatic $\beta$-cells deficient in inducible nitric oxide synthase. Biochem. Biophys. Res. Commun. 281:396-403.

Andrews, R. C., and B. R. Walker. 1999. Glucocorticoids and insulin resistance: Old hormones, new targets. Clin. Sci. 96:513-523.

Bannerman, D. D., M. J. Paape, W. R. Hare, and E. J. Sohn. 2003. Increased levels of LPS-binding protein in bovine blood and milk following bacterial lipopolysaccharide challenge. J. Dairy Sci. $86: 3128-3137$.

Beishuizen, A., and L. G. Thijs. 2003. Endotoxin and the hypothalamo-pituitary adrenal (HPA) axis. J. Endotoxin Res. 9:3-24.

Bionaz, M., and J. J. Loor. 2008. Gene networks driving bovine milk fat synthesis during the lactation cycle. BMC Genomics 9:366.

Blum, J. W., F. Jans, W. Moses, D. Fröhli, M. Zemp, M. Wanner, I. C. Hart, R. Thun, and U. Keller. 1985. Twenty-four-hour pattern of blood hormone and metabolite concentrations in high-yielding dairy cows: Effects of feeding low or high amounts of starch, or crystalline fat. Zentralbl. Veterinärmed. A 32:401-418.

Bobe, G., J. W. Young, and D. C. Beitz. 2004. Invited review: Pathology, etiology, prevention, and treatment of fatty liver in dairy cows. J. Dairy Sci. 87:3105-3124.

Bruckmaier, R. M., M. Schällibaum, and J. W. Blum. 1993. Escherichia coli endotoxin-induced mastitis in dairy cows: Changes and importance of insulin-like growth factor1 and oxytocin. Milchwissenschaft 48:374-378.

Duffield, T. F., K. D. Lissemore, B. W. McBride, and K. E. Leslie. 2009. Impact of hyperketonemia in early lactation dairy cows on health and production. J. Dairy Sci. 92:571-580.

Eizirik, D. L., S. Sandler, N. Welsh, L. Juntti-Berggren, and P.-O. Berggren. 1995. Interleukin-1 $\beta$-induced stimulation of insulin release in mouse pancreatic islets is related to diacylglycerol production and protein kinase $\mathrm{C}$ activation. Mol. Cell. Endocrinol. 111:159-165. 
Graber, M., S. Kohler, T. Kaufmann, M. G. Doherr, R. M. Bruckmaier, and H. A. van Dorland. 2010. A field study on characteristics and diversity of gene expression in the liver of dairy cows during the transition period. J. Dairy Sci. 93:5200-5215.

Gross, J., H. A. van Dorland, R. M. Bruckmaier, and F. J. Schwarz. 2011. Performance and metabolic profile of dairy cows during a lactational and deliberately induced negative energy balance with subsequent realimentation. J. Dairy Sci. 94:1820-1830.

Kreipe, L., M. C. M. B. Vernay, A. Oppliger, O. Wellnitz, R. M. Bruckmaier, and H. A. van Dorland. 2011. Induced hypoglycemia for 48 hours indicates differential glucose and insulin effects on liver metabolism in dairy cows. J. Dairy Sci. 94:5435-5448.

Kremer, W. D. J., C. Burvenich, E. N. Noordhuizen-Stassen, F. J. Grommers, Y. H. Schukken, R. Heeringa, and A. Brand. 1993. Severity of experimental Escherichia coli mastitis in ketonemic and non-ketonemic dairy cows. J. Dairy Sci. 76:3428-3436.

Lehmann, M., O. Wellnitz, and R. M. Bruckmaier. 2013. Concomitant lipopolysaccharide-induced transfer of blood-derived components including immunoglobulins into milk. J. Dairy Sci. 96:889-896.

Lehtolainen, T., S. Suominen, T. Kutila, and S. Pyörälä. 2003. Effect of intramammary Escherichia coli endotoxin in early- vs. latelactating dairy cows. J. Dairy Sci. 86:2327-2333.

Memon, R. A., K. R. Feingold, A. H. Moser, W. Doerrler, S. Adi, C. A. Dinarello, and C. Grunfeld. 1992. Differential effects of interleukin-1 and tumor necrosis factor on ketogenesis. Am. J. Physiol. 263:E301-E309.

Müller, M. J., U. Paschen, and H. J. Seitz. 1984. Effect of ketone bodies on glucose production and utilization in the miniature pig. J. Clin. Invest. 74:249-261.

Muller, W. A., G. R. Faloona, and R. H. Unger. 1971. The influence of the antecedent diet upon glucagon and insulin secretion. N. Engl. J. Med. 285:1450-1454.

Oltenacu, P. A., and I. Ekesbo. 1994. Epidemiological study of clinical mastitis in dairy cattle. Vet. Res. 25:208-212.

Ospina, P. A., D. V. Nydam, T. Stokol, and T. R. Overton. 2010. Evaluation of nonesterified fatty acids and $\beta$-hydroxybutyrate in transition dairy cattle in the Northeastern United States: Critical thresholds for prediction of clinical diseases. J. Dairy Sci. 93:546-554.

Palmquist, D. L., C. L. Davis, R. E. Brown, and D. S. Sachan. 1969. Availability and metabolism of various substrates in ruminants. V. Entry rate into the body and incorporation into milk fat of $\mathrm{D}(-)$ ß-hydroxybutyrate. J. Dairy Sci. 52:633-638.

Sandholm, M. 1976. Coagulation of serum by glutaraldehyde. Clin. Biochem. 9:39-41.

Schlumbohm, C., and J. Harmeyer. 2004. Hyperketonemia impairs glucose metabolism in pregnant and nonpregnant ewes. J. Dairy Sci. 87:350-358.

Schmitz, S., M. W. Pfaffl, H. H. D. Meyer, and R. M. Bruckmaier. 2004. Short-term changes of mRNA abundance of various inflam- matory factors and milk proteins in mammary tissue during LPSinduced mastitis. Domest. Anim. Endocrinol. 26:111-126.

Stouthard, J. M. L., J. A. Romijn, T. Van der Poll, E. Endert, S. Klein, P. J. M. Bakker, C. H. N. Veenhof, and H. P. Sauerwein. 1995. Endocrinologic and metabolic effects of interleukin-6 in humans. Am. J. Physiol. 268:E813-E819.

Suzuki, Y., H. Takahashi, M. Fukuda, H. Hino, K. Kobayashi, J. Tanaka, and E. Ishii. 2009. $\beta$-Hydroxybutyrate alters GABA-transaminase activity in cultured astrocytes. Brain Res. 1268:17-23.

van Dorland, H. A., S. Richter, I. Morel, M. G. Doherr, N. Castro, and R. M. Bruckmaier. 2009. Variation in hepatic regulation of metabolism during the dry period and in early lactation in dairy cows. J. Dairy Sci. 92:1924-1940.

Vernay, M. C. M. B., O. Wellnitz, L. Kreipe, H. A. van Dorland, and R. M. Bruckmaier. 2012. Local and systemic response to intramammary lipopolysaccharide challenge during long-term manipulated plasma glucose and insulin concentrations in dairy cows. J. Dairy Sci. 95:2540-2549.

Vicari, T., J. J. G. C. van den Borne, W. J. J. Gerrits, Y. Zbinden, and J. W. Blum. 2008. Postprandial blood hormone and metabolite concentrations influenced by feeding frequency and feeding level in veal calves. Domest. Anim. Endocrinol. 34:74-88.

Waldron, M. R., A. E. Kulick, A. W. Bell, and T. R. Overton. 2006. Acute experimental mastitis is not causal toward the development of energy-related metabolic disorders in early postpartum dairy cows. J. Dairy Sci. 89:596-610.

Waldron, M. R., T. Nishida, B. J. Nonnecke, and T. R. Overton. 2003. Effect of lipopolysaccharide on indices of peripheral and hepatic metabolism in lactating cows. J. Dairy Sci. 86:3447-3459.

Weir, G. C., S. D. Knowlton, R. F. Atkins, F. X. McKennan, and D. B. Martin. 1976. Glucagon secretion from the perfused pancreas of streptozotocin-treated rats. Diabetes 25:275-282.

Wendt, A., B. Birnir, K. Buschard, J. Gromada, A. Salehi, S. Sewing, P. Rorsman, and M. Braun. 2004. Glucose inhibition of glucagon secretion from rat alpha-cells is mediated by GABA released from neighboring beta-cells. Diabetes 53:1038-1045.

Werling, D., F. Sutter, M. Arnold, G. Kun, P. C. J. Tooten, E. Gruys, M. Kreuzer, and W. Langhans. 1996. Characterisation of the acute phase response of heifers to a prolonged low dose infusion of lipopolysaccharide. Res. Vet. Sci. 61:252-257.

Zarrin, M., L. De Matteis, M. C. M. B. Vernay, O. Wellnitz, H. A. van Dorland, and R. M. Bruckmaier. 2013. Long-term elevation of $\beta$-hydroxybutyrate in dairy cows through infusion: Effects on feed intake, milk production, and metabolism. J. Dairy Sci. 96:29602972.

Zarrin, M., O. Wellnitz, H. A. van Dorland, and R. M. Bruckmaier. 2014. Induced hyperketonemia affects the mammary immune response during lipopolysaccharide challenge in dairy cows. J. Dairy Sci. 97:330-339. 